\title{
Onset of action of indacaterol in patients with COPD: Comparison with salbutamol and salmeterol-fluticasone
}

This article was published in the following Dove Press journal:

International Journal of Chronic Obstructive Pulmonary Disease

4 September 2010

Number of times this article has been viewed

\author{
Beatrix Balint ${ }^{1}$ \\ Henrik Watz ${ }^{2}$ \\ Carolynn Amos ${ }^{3}$ \\ Roger Owen ${ }^{3}$ \\ Mark Higgins ${ }^{3}$ \\ Benjamin Kramer ${ }^{4}$ \\ On behalf of the INSURE* \\ Study Investigators \\ 'Csongrád Megyei Önkormányzat \\ Mellkasi Betegségek Szakkórháza, \\ Deszk, Hungary; ${ }^{2}$ Pulmonary Research \\ Institute, Hospital Grosshansdorf, \\ Grosshansdorf, Germany; ${ }^{3}$ Novartis \\ Horsham Research Centre, Horsham, \\ West Sussex, UK; ${ }^{4}$ Novartis \\ Pharmaceuticals, East Hanover, NJ, \\ USA; *Indacaterol: starting quickly and \\ remaining effective in COPD
}

Correspondence: Benjamin Kramer Novartis Pharmaceuticals Corporation, One Health Plaza, East Hanover, NJ 07936-1080, USA

Tel +l 8627789479

$\mathrm{Fax}+$ I 973 78I 8265

Email benjamin.kramer@novartis.com
Background: Indacaterol is a novel, inhaled once-daily ultra-long-acting $\beta_{2}$-agonist for the treatment of chronic obstructive pulmonary disease (COPD).

Objectives: This study compared the onset of action of single doses of indacaterol 150 and $300 \mu \mathrm{g}$ with salbutamol $200 \mu \mathrm{g}$, salmeterol-fluticasone $50 / 500 \mu \mathrm{g}$, and placebo in moderateto-severe COPD patients.

Methods: This was a multicenter, randomized, double-blind, placebo-controlled crossover study. The primary variable was forced expiratory volume in one second $\left(\mathrm{FEV}_{1}\right)$ at five minutes postdose.

Results: Out of 89 patients randomized (mean age 62 years), 86 completed the study. At five minutes postdose, both indacaterol doses were statistically and clinically superior to placebo $(P<0.001)$, with treatment-placebo differences in $\mathrm{FEV}_{1}$ of $100(95 \%$ confidence interval [CI] 70-130) $\mathrm{mL}$ and $120(95 \% \mathrm{CI} 90-150) \mathrm{mL}$ for indacaterol 150 and $300 \mu \mathrm{g}$, respectively. $\mathrm{FEV}_{1}$ at five minutes postdose with both indacaterol doses was numerically higher than for salbutamol (10 and $30 \mathrm{~mL}$ for indacaterol 150 and $300 \mu \mathrm{g}$, respectively) and significantly higher than for salmeterol-fluticasone (50 mL, $P=0.003 ; 70 \mathrm{~mL}, P<0.001$, respectively). Moreover, both indacaterol doses showed significantly higher $\mathrm{FEV}_{1}$ than placebo $(P<0.001)$ at all postdose time points. The numbers of patients with an $\mathrm{FEV}_{1}$ increase of at least $12 \%$ and $200 \mathrm{~mL}$ at five minutes postdose were 16 (18.8\%), 24 (27.6\%), $20(23.3 \%), 8(9.1 \%)$, and 3 (3.4\%) for indacaterol 150 and $300 \mu \mathrm{g}$, salbutamol $200 \mu \mathrm{g}$, salmeterol-fluticasone 50/500 $\mu \mathrm{g}$, and placebo, respectively.

Conclusions: Single doses of indacaterol 150 and $300 \mu \mathrm{g}$ demonstrated a fast onset of action similar to that for salbutamol and faster than that for salmeterol-fluticasone.

Keywords: indacaterol, onset of action, chronic obstructive pulmonary disease

\section{Introduction}

Chronic obstructive pulmonary disease (COPD), being a condition associated with increased morbidity and mortality, causes a substantial and increasing burden to society in many countries. ${ }^{1,2}$ The Global Initiative for Chronic Obstructive Lung Disease (GOLD) guideline ${ }^{3}$ recommends regular use of bronchodilators for symptomatic management of COPD, including inhaled $\beta_{2}$-agonists and anticholinergics. ${ }^{3}$ As with all chronic diseases, nonadherence to treatment is common in patients with COPD, potentially leading to adverse health outcomes and reduced quality of life. ${ }^{4}$ Characteristics of COPD medications and regimens may often contribute to nonadherence, and therefore should be considered when selecting the appropriate treatment for a patient. In general, more complex regimens result in suboptimal adherence, ${ }^{5}$ with frequency of dosing regarded as one of the principal factors that negatively affect adherence. ${ }^{6}$ 
In addition, adherence is lower for medications that do not have an immediate effect on symptoms. ${ }^{7}$

Indacaterol is a novel, inhaled once-daily ultra-longacting $\beta_{2}$-agonist (LABA) ${ }^{8}$ for the treatment of COPD. In preclinical studies, the onset of action of indacaterol was similar to that of salbutamol and of formoterol, and was significantly faster than that of salmeterol. ${ }^{9}$ In previous clinical studies, indacaterol has demonstrated 24-hour bronchodilation on once-daily dosing, along with a good overall safety and tolerability profile. ${ }^{10-12}$ The present study was conducted to evaluate the onset of action of single doses of indacaterol 150 and $300 \mu \mathrm{g}$ in comparison with that of salbutamol $200 \mu \mathrm{g}$ (the standard "fast-onset" bronchodilator), the combination of salmeterol $50 \mu \mathrm{g}$ and fluticasone $500 \mu \mathrm{g}$ (salmeterol-fluticasone 50/500 $\mu \mathrm{g}$ ), and placebo in patients with moderate-to-severe COPD.

\section{Methods}

This was an international, multicenter, randomized, doubleblind, placebo-controlled, crossover, single-dose study. Institutional review board or independent ethics committee approval was obtained from each participating study center. The study was conducted in accordance with the Declaration of Helsinki (1989) and local applicable laws and regulations. All patients provided written informed consent prior to participation in the study.

\section{Study population}

Patients of either gender, aged $\geq 40$ years, with moderateto-severe COPD (according to the GOLD 2005 guideline), smoking history of $\geq 20$ pack years, postbronchodilator forced expiratory volume in one second $\left(\mathrm{FEV}_{1}\right) \geq 30 \%$ but $<80 \%$ of the predicted normal value, and postbronchodilator

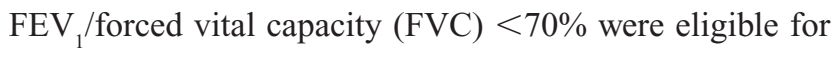
enrolment in the study.

Patients were excluded from the study if they had any concomitant pulmonary disease, type I diabetes or uncontrolled type II diabetes, uncontrolled hypertension, unstable ischemic heart disease, or malignancy. Patients who had a history of asthma, had been hospitalized for a COPD exacerbation within six weeks prior to screening or during the run-in period, or had experienced respiratory tract infection within six weeks prior to screening, were also excluded.

The following medications were prohibited at any time during the study (the minimum washout period is shown in brackets): long-acting anticholinergics (seven days), short-acting anticholinergics (eight hours), fixed-dose combination of a $\beta_{2}$-agonist and an inhaled corticosteroid
(ICS, 48 hours), fixed-dose combination of a short-acting $\beta_{2}$-agonist and a short-acting anticholinergic (eight hours), other LABAs (48 hours), short-acting $\beta_{2}$-agonists (other than those prescribed in the study, six hours), xanthine derivatives (one week), and parenteral or oral corticosteroids (one month). Patients on fixed-dose combinations of a $\beta_{2}$-agonist and an ICS were to be switched to the equivalent ICS prior to the runin period, with the dose and dosage regimen to remain unchanged for the duration of the study. Patients on ICS at the screening visit were to continue ICS for the duration of the study, again at a dose and regimen to remain unchanged.

\section{Study design and treatments}

The study comprised a prescreening visit, a 14-day screening/run-in period, and five single-dose treatment periods. During the prescreening visit, patients' ongoing COPD medications were reviewed and, if necessary, any prohibited medication was adjusted to an allowable COPD therapy. After the screening visit, patients entered into a 14-day run-in period, during which their eligibility was assessed. At baseline, patients were randomized equally (using a validated automated system) to one of five treatment sequences to receive indacaterol $150 \mu \mathrm{g}$ and $300 \mu \mathrm{g}$ delivered via a single-dose dry powder inhaler, salbutamol $200 \mu \mathrm{g}$ via the manufacturer's proprietary multidose dry powder inhaler, salmeterol-fluticasone 50/500 $\mu \mathrm{g}$ fixeddose combination via the manufacturer's proprietary multidose dry powder inhaler, and placebo. Each treatment sequence comprised five double-blind, single-dose treatment periods, with treatment periods separated by a 4- to 7-day washout period. At 4-7 days after the last treatment visit, patients were contacted by telephone for a study completion call.

Patients inhaled through three different devices on each visit (one inhalation from a single-dose dry powder inhaler and one from each of the two multidose dry powder inhalers used in the study), with the order of devices randomly assigned at the start of the study. Treatment allocation was concealed from the patients, investigating staff, and the clinical trial team by the use of matching placebo inhalers all identical in packaging, labeling, and schedule of administration. An unblinded pharmacist (or designee) prepared the individual patient-specific packs from supplied bulk medication. Salbutamol was the only rescue medication permitted throughout the study, although visits had to be rescheduled if salbutamol was taken within six hours prior to the start of the visit. 


\section{Assessments and outcomes \\ Efficacy}

All efficacy evaluations were based on spirometric assessment of lung function, performed at 50 and 15 minutes predose and at 5, 15, and 30 minutes, and at 1 and 2 hours postdose. The postdose time was measured from the time the first device was used at each study visit (the three devices were used in a randomized order, as described above). All spirometry equipment and spirometric testing were in accordance with the American Thoracic Society/European Respiratory Society standards. ${ }^{13}$

The primary efficacy variable was $\mathrm{FEV}_{1}$ at five minutes postdose. The primary objective was to compare indacaterol 150 and $300 \mu \mathrm{g}$ and placebo in terms of $\mathrm{FEV}_{1}$ at five minutes postdose. The secondary objectives were to compare indacaterol 150 and $300 \mu \mathrm{g}$ with salbutamol $200 \mu \mathrm{g}$ and salmeterol-fluticasone 50/500 $\mu \mathrm{g}$, and to compare salmeterolfluticasone 50/500 $\mu \mathrm{g}$ with salbutamol $200 \mu \mathrm{g}$ in terms of $\mathrm{FEV}_{1}$ at five minutes postdose. The other efficacy variables were $\mathrm{FEV}_{1}$ at other scheduled time points; the proportion of patients with at least $10 \%, 12 \%$, and $15 \%$ increase in $\mathrm{FEV}_{1}$ from baseline to each scheduled time point; and the proportion of patients with at least a $12 \%$ and $200 \mathrm{~mL}$ increase in $\mathrm{FEV}_{1}$ from baseline to each scheduled time point.

\section{Safety}

Safety assessments included recording of adverse events and serious adverse events, along with evaluation of their severity, duration, and relationship to study drug. In addition, samples were collected for hematology and blood chemistry (including serum potassium and blood glucose), and vital signs and electrocardiogram assessments were recorded.

\section{Sample size calculation and statistical analysis}

It was estimated that 53 patients were needed to complete the study, assuming a difference of $120 \mathrm{~mL}$ between each indacaterol dose and placebo in terms of $\mathrm{FEV}_{1}$ at five minutes postdose, a standard deviation of $240 \mathrm{~mL}$, a two-sided significance level of 5\% (adjusted to $2.5 \%$ using a Bonferroni correction for the two main treatment comparisons, that is, indacaterol [150 and $300 \mu \mathrm{g}$ ] versus placebo), and a power of $90 \%$. As there were five treatment sequences and six inhaler orders for individual treatment sequences, a total of 60 patients with evaluable measurements were required in order to have an equal number of patients per inhaler order and per treatment sequence. Allowing for a $15 \%$ dropout rate and with the number inflated to ensure balance across the treatment sequences, it was calculated that 75 patients needed to be randomized.

The primary efficacy analysis was performed on a modified intent-to-treat population that included all randomized patients who received at least one dose of study drug (the modification was that patients were analyzed according to treatment received in each treatment period). The safety population, which was used in the analysis of all safety variables, included all patients who received at least one dose of study drug.

The primary efficacy variable, $\mathrm{FEV}_{1}$ at five minutes postdose, was analyzed using a mixed model, with treatment group and period modeled as fixed effects, patient as a random effect, and period baseline $\mathrm{FEV}_{1}$ as a covariate. Period baseline FEV 1 was defined as the average of the $\mathrm{FEV}_{1}$ values measured 50 and 15 minutes prior to study drug administration in each treatment period. For the primary variable, estimated least squares means and treatment differences with associated 95\% confidence intervals (CIs) are presented. A multiplicity adjustment for the two main treatment comparisons in the study was made using a stepdown Dunnett's test implemented in a closed test procedure. Similar mixed-effect models were used to analyze $\mathrm{FEV}_{1}$ at the other time points.

The proportion of patients with at least a $10 \%, 12 \%$, and $15 \%$ increase in $\mathrm{FEV}_{1}$ from baseline at each scheduled time point, and the proportion of patients with at least a $12 \%$ and $200 \mathrm{~mL}$ increase in $\mathrm{FEV}_{1}$ from baseline at each scheduled time point, were summarized using descriptive statistics and analyzed by logistic regression for each time point. The logistic regression model included terms for period, treatment, and period baseline as fixed effects and patient as a random effect. The estimated odds ratios are presented along with the associated $95 \%$ CIs and $P$ values. All analyses were performed using SAS statistical software (version 9.1.3 for Windows; SAS Institute Inc., Cary, NC).

\section{Results \\ Patient disposition, demographics, and baseline characteristics}

Of 114 patients screened, 89 were eligible to participate in the study. All eligible patients were randomized to treatment sequences, and no patient received the study drug in error; thus, the safety population was identical to the modified intent-to-treat population. Eighty-six (96.6\%) patients completed the study, while three (3.4\%) patients discontinued from the study (one each due to withdrawal of consent, loss to follow-up, and protocol deviation). 
Demographic and baseline clinical characteristics are summarized in Table 1. More than half of the patients (61.8\%) were aged $<65$ years, the majority was Caucasian, and more than half were male. All patients were current or former smokers.

Table I Demographic summary and baseline clinical characteristics (safety population)

\begin{tabular}{|c|c|}
\hline Variable & Total, $\mathbf{n}=\mathbf{8 9}$ \\
\hline \multicolumn{2}{|l|}{ Age (years) } \\
\hline Mean \pm SD & $62.3 \pm 8.37$ \\
\hline Range & $43-79$ \\
\hline \multicolumn{2}{|l|}{ Sex, n (\%) } \\
\hline Male & $54(60.7)$ \\
\hline Female & $35(39.3)$ \\
\hline \multicolumn{2}{|l|}{ Race, n (\%) } \\
\hline Caucasian & $88(98.9)$ \\
\hline Black & $\mathrm{I}(\mathrm{I} . \mathrm{I})$ \\
\hline \multicolumn{2}{|l|}{ Weight (kg) } \\
\hline Mean \pm SD & $80.1 \pm 17.27$ \\
\hline Range & $49.0-120.0$ \\
\hline \multicolumn{2}{|l|}{ Duration of COPD (years) } \\
\hline Mean \pm SD & $6.8 \pm 5.8 \mathrm{I}$ \\
\hline Range & $0.1-27.0$ \\
\hline \multicolumn{2}{|l|}{ ICS use, $n(\%)$} \\
\hline Yes & $49(55.1)$ \\
\hline No & $40(44.9)$ \\
\hline \multicolumn{2}{|c|}{ COPD medication discontinued prior } \\
\hline \multicolumn{2}{|l|}{ to start of study treatment, $\mathrm{n}(\%)$} \\
\hline Long-acting anticholinergic & $31(34.8)$ \\
\hline$\beta_{2}$-agonist plus steroid & $28(31.5)$ \\
\hline Long-acting $\beta_{2}$-agonist & $23(25.8)$ \\
\hline$\beta_{2}$-agonist plus anticholinergic & 14 (I5.7) \\
\hline Xanthine & $9(10.1)$ \\
\hline Short-acting anticholinergic & $4(4.5)$ \\
\hline \multicolumn{2}{|l|}{ Smoking history, $\mathrm{n}(\%)$} \\
\hline Exsmoker & $40(44.9)$ \\
\hline Smoker & $49(55.1)$ \\
\hline \multicolumn{2}{|c|}{ Postbronchodilator $\mathrm{FEV}_{1}(\mathrm{~L})$ at screening } \\
\hline Mean \pm SD & $1.48 \pm 0.420$ \\
\hline Range & $0.77-2.60$ \\
\hline \multicolumn{2}{|c|}{ Postbronchodilator FVC $(\mathrm{L})$ at screening } \\
\hline Mean \pm SD & $2.94 \pm 0.85 I$ \\
\hline Range & $1.21-5.24$ \\
\hline \multicolumn{2}{|c|}{ Postbronchodilator FEV (\% predicted) at screening } \\
\hline Mean \pm SD & $53.5 \pm 12.73$ \\
\hline Range & $31.6-83.8$ \\
\hline \multicolumn{2}{|c|}{ Postbronchodilator FEV $/$ /FVC at screening (\%) } \\
\hline Mean \pm SD & $51.4 \pm 9.08$ \\
\hline Range & $27.4-68.8$ \\
\hline \multicolumn{2}{|c|}{$\mathrm{FEV}_{1}$ reversibility (\% increase) at screening } \\
\hline Mean \pm SD & $9.1 \pm 12.22$ \\
\hline Median & 6.1 \\
\hline $25^{\text {th }}-75^{\text {th }}$ quartile & $0.9-16.5$ \\
\hline Range & $-22.8-41.0$ \\
\hline
\end{tabular}

Note: FEV, reversibility at screening was measured 15-30 minutes after inhalation of $400 \mu \mathrm{g}$ salbutamol.

Abbreviations: SD, standard deviation; ICS, inhaled corticosteroids; $\mathrm{FEV}_{1}$, forced expiratory volume in one second; FVC, forced vital capacity; COPD, chronic obstructive pulmonary disease.

\section{Efficacy}

For the primary efficacy variable $\left(\mathrm{FEV}_{1}\right.$ at five minutes postdose), the least squares mean values for indacaterol 150 and $300 \mu \mathrm{g}$ were higher than that for placebo by 100 and $120 \mathrm{~mL}$, respectively $(P<0.001$, Figures 1 and 2$)$. Both indacaterol doses showed a numerically higher $\mathrm{FEV}_{1}$ at five minutes postdose than salbutamol (differences of 10 and $30 \mathrm{~mL}$ for indacaterol 150 and $300 \mu \mathrm{g}$, respectively, versus salbutamol, Figure 2). Moreover, both indacaterol doses produced significantly higher $\mathrm{FEV}_{1}$ at five minutes postdose than salmeterol-fluticasone $(50 \mathrm{~mL}, P=0.003$ and $70 \mathrm{~mL}$, $P<0.001$, Figure 2).

Serial measurements of $\mathrm{FEV}_{1}$ at all postdose time points are shown in Figure 3. Both indacaterol doses showed significantly higher $\mathrm{FEV}_{1}$ than placebo $(P<0.001)$ at all postdose time points, significantly higher than salmeterol-fluticasone $(P<0.05)$ at five and 15 minutes postdose, and numerically $(150 \mu \mathrm{g})$ or statistically $(300 \mu \mathrm{g})$ higher than salmeterolfluticasone at 30 minutes postdose (Figure 4 ). The difference between indacaterol $300 \mu \mathrm{g}$ and salbutamol was statistically significant at two hours postdose $(P<0.001)$.

The proportion of patients with at least a $10 \%, 12 \%$, or $15 \%$ increase in $\mathrm{FEV}_{1}$ from baseline at five minutes postdose was higher in both indacaterol groups compared with salmeterol-fluticasone $(P<0.01)$, and similar to salbutamol (Table 2). At 30 minutes postdose, the proportion of patients with at least a $10 \%, 12 \%$, or $15 \%$ increase in $\mathrm{FEV}_{1}$ was higher in both indacaterol groups compared with placebo, with the proportions in the indacaterol $300 \mu \mathrm{g}$ group higher than those in the salmeterol-fluticasone group (Table 3). The proportion was also higher in both indacaterol groups than placebo at five and 15 minutes, and at one and two hours postdose $(P<0.001$ for all). The proportions of patients with at least a $12 \%$ and $200 \mathrm{~mL}$ increase in $\mathrm{FEV}_{1}$ from baseline at five minutes postdose in the indacaterol $150 \mu \mathrm{g}$, indacaterol $300 \mu \mathrm{g}$, and salbutamol $200 \mu \mathrm{g}$ groups were higher than that in the salmeterolfluticasone $50 / 500 \mu \mathrm{g}$ and placebo groups $(P<0.05$ for all, Figure 5).

\section{Safety}

Overall, adverse events were reported in 3/86 (3.5\%), 3/87 (3.4\%), 4/86 (4.7\%), 6/88 (6.8\%), and 4/87 (4.6\%) patients taking indacaterol $150 \mu \mathrm{g}$, indacaterol $300 \mu \mathrm{g}$, salbutamol $200 \mu \mathrm{g}$, salmeterol-fluticasone 50/500 $\mu \mathrm{g}$, and placebo, respectively. All reported adverse events were mild or moderate in severity, and none were suspected of being related to study drug. There were no deaths or serious adverse events 


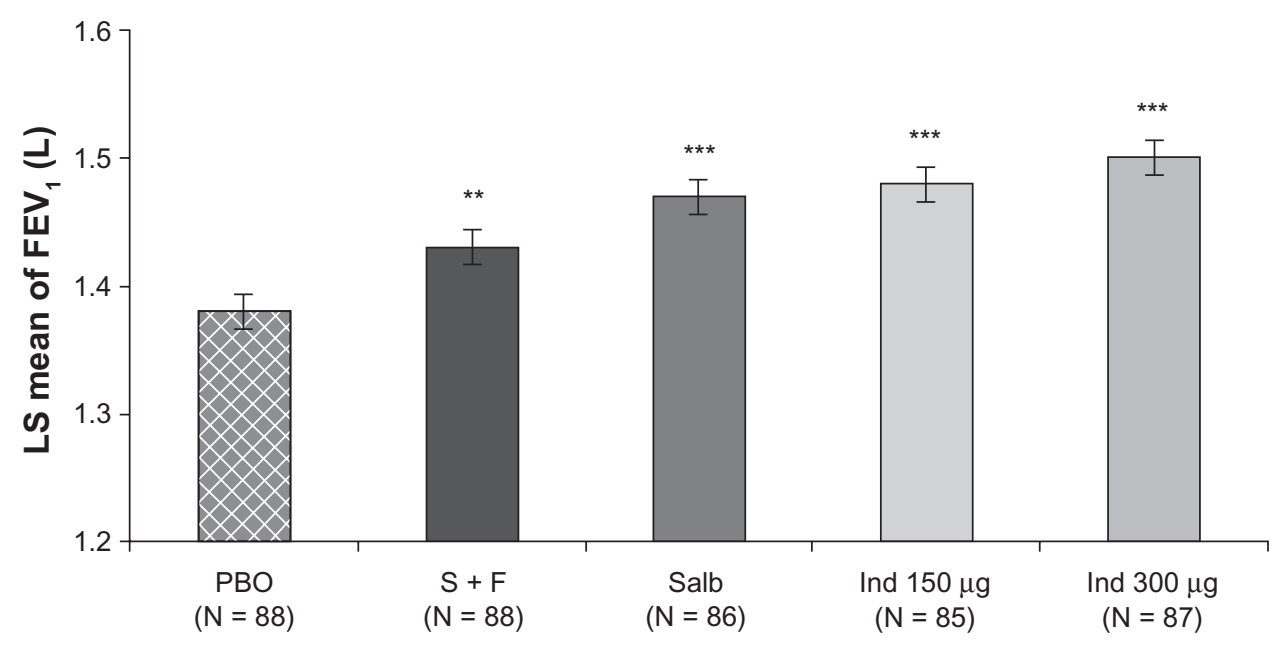

Figure I Least squares mean $\mathrm{FEV}_{1} \pm$ standard error of the mean at five minutes postdose.

Note: Differences versus placebo significant at $* * P<0.01$ and $* * * P<0.001$.

Abbreviations: Ind, indacaterol; LS, least squares; PBO, placebo; Salb, salbutamol; S + F, salmeterol-fluticasone.

during this study. No patient discontinued from the study due to adverse events. Notably, high pulse rate ( $>90$ beats per minute) and systolic blood pressure $(>140 \mathrm{mmHg})$ were more frequently reported for patients taking placebo than for those taking indacaterol. No patient in the study had an absolute corrected QT (Fridericia's) value of $>500 \mathrm{msec}$ or a change from baseline of $60 \mathrm{msec}$. Furthermore, no patient had newly occurring or worsening clinically notable values for serum potassium (minimum postbaseline value $<3.0 \mathrm{mmol} / \mathrm{L}$ ) during this study, and only three patients (one patient each who took indacaterol 150 and $300 \mu \mathrm{g}$ and salmeterol-fluticasone $50 / 500 \mu \mathrm{g}$ ) had newly occurring or

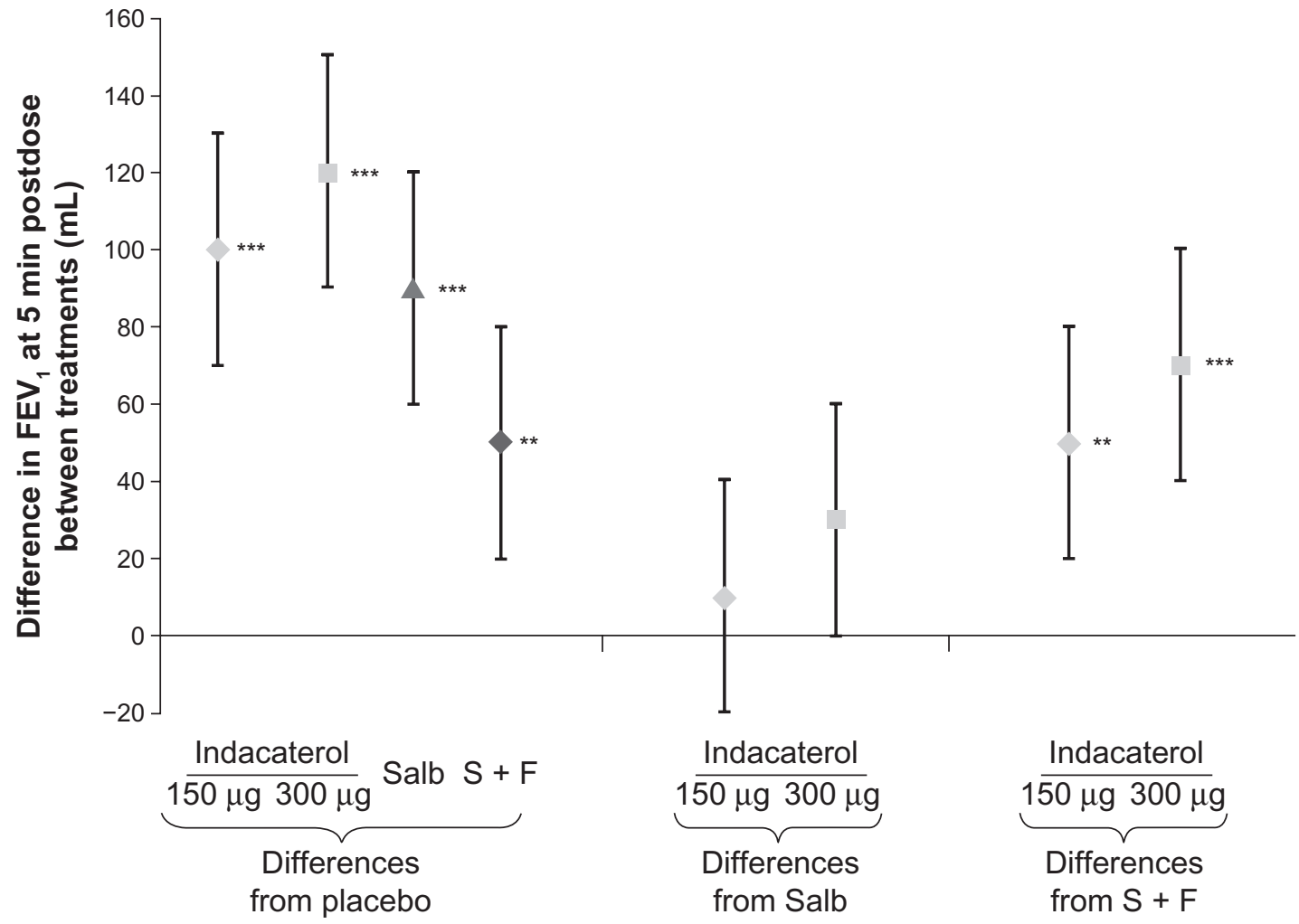

Figure 2 Least squares mean treatment differences ( $\pm 95 \%$ confidence interval) in FEV at five minutes postdose. Note: Differences significant at $* * P<0.01$ and $* * * p<0.001$.

Abbreviations: $\mathrm{FEV}_{1}$, forced expiratory volume in one second; Salb, salbutamol; S + F, salmeterol-fluticasone. 


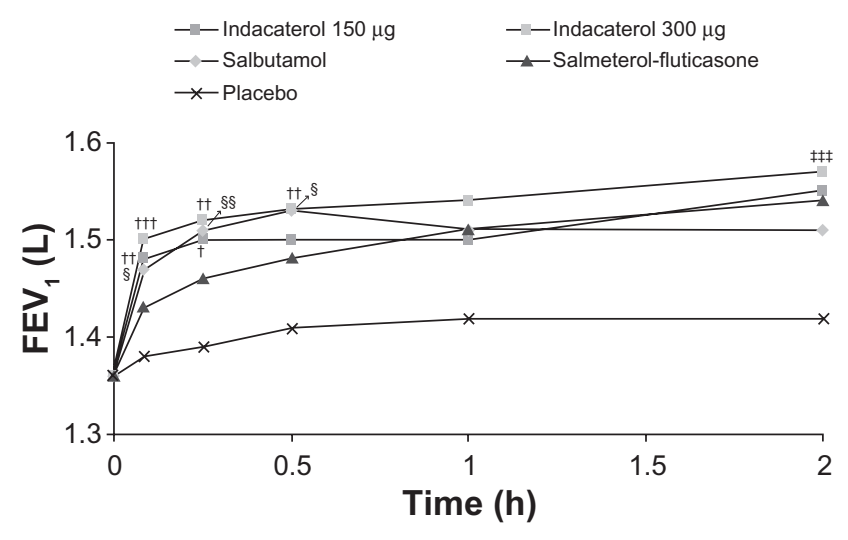

Figure 3 Serial least squares mean FEV, over two hours.

Notes: $P<0.001$ for both indacaterol doses versus placebo at all time points; $P<0.00$ I for salbutamol versus placebo at all time points; $P<0.0$ I for salmeterolfluticasone at all time points; ${ }^{\dagger} P<0.05$; ${ }^{\text {tt }} P<0.0$ I; ${ }^{\text {ttt }} \mathrm{P}<0.00 \mathrm{l}$ for indacaterol versus salmeterol-fluticasone; ${ }^{\ddagger \ddagger P}<0.001$ indacaterol versus salbutamol; $\$ P<0.05$; $\$ \S p<0.01$ for salbutamol versus salmeterol-fluticasone.

Abbreviations: $\mathrm{FEV}_{1}$, forced expiratory volume in one second; $h$, hours.

worsening of clinically notable values for blood glucose (maximum postbaseline value $>9.99 \mathrm{mmol} / \mathrm{L}$ ).

\section{Discussion}

As with many chronic conditions, adherence to treatment is low in COPD, which is perhaps a reflection of the high rate of comorbid conditions and consequent polypharmacy. Although indacaterol is being developed for maintenance treatment of COPD, and not as rescue medication, fast onset on the first dose may help patients perceive an immediate symptomatic benefit. This, together with the sustained 24-hour duration of bronchodilation ${ }^{14}$ and a good overall safety and tolerability profile, ${ }^{12}$ which have been observed in other indacaterol clinical studies, may lead to improved patient adherence. ${ }^{15}$

This study was therefore designed to compare the onset of action of single doses of indacaterol 150 and $300 \mu \mathrm{g}$ with salbutamol, salmeterol-fluticasone, and placebo. The study was conducted as planned, with $96.6 \%$ of randomized patients completing their assigned treatments. This study achieved all primary and secondary objectives. For the primary efficacy variable $\left(\mathrm{FEV}_{1}\right.$ at five minutes postdose), both indacaterol doses were superior to placebo, with treatment-placebo differences of 100 and $120 \mathrm{~mL}$ for the 150 and $300 \mu \mathrm{g}$ doses, respectively. Such differences (ie, $\geq 100 \mathrm{~mL}$ ) have been described as ones that patients can perceive, and therefore can be considered clinically relevant. ${ }^{16}$ Furthermore, the bronchodilator efficacy of both indacaterol doses at this time point was similar to that

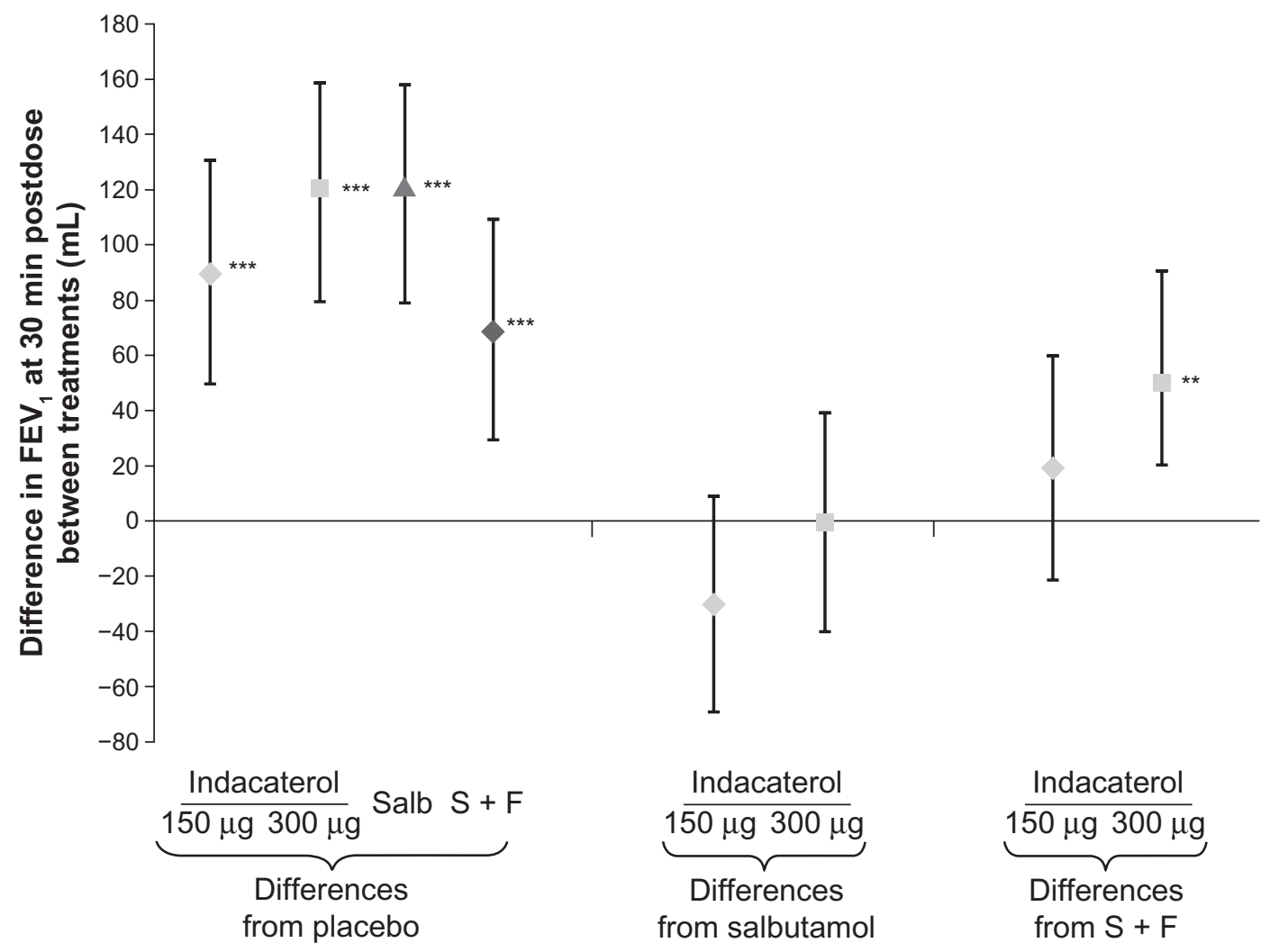

Figure 4 Least squares mean treatment differences ( $\pm 95 \%$ confidence interval) in $\mathrm{FEV}$, at 30 minutes postdose. Note: Differences significant at $* * p<0.01$ and $* * * p<0.001$.

Abbreviations: $\mathrm{FEV}_{1}$, forced expiratory volume in one second; Salb, salbutamol; $\mathrm{S}+\mathrm{F}$, salmeterol-fluticasone. 
Table 2 Number and proportion of patients with at least $10 \%$,

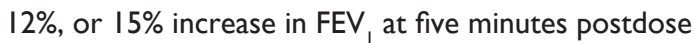

\begin{tabular}{|c|c|c|c|}
\hline & \multicolumn{3}{|c|}{ Percentage increase in FEV, $\mathbf{n}(\%)$} \\
\hline & $10 \%$ & $12 \%$ & $15 \%$ \\
\hline $\begin{array}{l}\text { Indacaterol } \\
150 \mu \mathrm{g}\end{array}$ & $35(4 I .2)^{* * *+t \dagger}$ & $24(28.2)^{* * * * t \dagger}$ & $17(20.0)^{* * *+t}$ \\
\hline $\begin{array}{l}\text { Indacaterol } \\
300 \mu \mathrm{g}\end{array}$ & $49(56.3)^{* * * * 1+t+1}$ & $40(46.0) * * *+++\pi \pi$ & $31(35.6)^{* * * * \neq+t+t \text { 9ाTा }}$ \\
\hline Salbutamol & $35(40.7) * * *+t \dagger$ & $31(36.0) * * * t+t$ & $21(24.4)^{* * * t+t}$ \\
\hline $\begin{array}{l}\text { Salmeterol- } \\
\text { fluticasone }\end{array}$ & $15(17.0)^{*}$ & $12(13.6)$ & $8(9.1)$ \\
\hline Placebo & $6(6.8)$ & $5(5.7)$ & $3(3.4)$ \\
\hline
\end{tabular}

Notes: $* P<0.05$; ***P $<0.001$ versus placebo; $¥ P<0.05$; $¥ \pm P<0.01$ versus

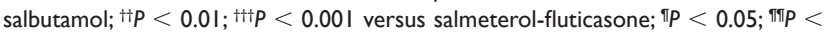
$0.01 ;$ TाTा $P<0.001$ versus indacaterol I $50 \mu \mathrm{g}$.

Abbreviations: $n$, number of patients who achieved an improvement; FEV , forced expiratory volume in one second.

observed with salbutamol, the 'gold standard' fast-acting rescue medication. Both indacaterol doses were statistically superior to placebo for the four other measures of onset of action, ie, the proportion of patients with at least a $10 \%$, $12 \%$, or $15 \%$ increase from baseline, or at least a $12 \%$ and $200 \mathrm{~mL}$ increase from baseline. The bronchodilator efficacy was at least as good as salbutamol for all of these endpoints, with the higher indacaterol dose $(300 \mu \mathrm{g})$ reaching statistical significance versus salbutamol for some endpoints.

The second active comparator selected for this study was the fixed-dose combination of salmeterol and fluticasone. Both indacaterol doses demonstrated a faster onset of action than salmeterol-fluticasone, with treatment-placebo differences in $\mathrm{FEV}_{1}$ at five minutes postdose of $50 \mathrm{~mL}$ with salmeterol-fluticasone, compared with the $100-120 \mathrm{~mL}$ seen with indacaterol. In other studies, the combination of salmeterol and fluticasone has been shown to provide better efficacy (even after a single dose) than salmeterol alone. ${ }^{17}$ It is notable, therefore, that in the current study in addition to faster onset

Table 3 Number and proportion of patients with at least 10\%, $12 \%$, or $15 \%$ increase in $\mathrm{FEV}$, at 30 minutes postdose

\begin{tabular}{|c|c|c|c|}
\hline & \multicolumn{3}{|c|}{ Percentage increase in FEV, $\mathbf{n}(\%)$} \\
\hline & $10 \%$ & $12 \%$ & $15 \%$ \\
\hline $\begin{array}{l}\text { Indacaterol } \\
150 \mu \mathrm{g}\end{array}$ & $39(45.9)^{* * *}$ & $33(38.8)^{* * *}$ & $26(30.6)^{* * *}$ \\
\hline $\begin{array}{l}\text { Indacaterol } \\
300 \mu \mathrm{g}\end{array}$ & $5 \mathrm{I}(58.6)^{* * *+\dagger}$ & $46(52.9) * * *++\pi$ & $38(43.7) * * *+t+q$ \\
\hline Salbutamol & $48(55.8)^{* * * \dagger}$ & $43(50.0)^{* * * \dagger}$ & $33(38.4)^{* * * \dagger}$ \\
\hline $\begin{array}{l}\text { Salmeterol- } \\
\text { fluticasone }\end{array}$ & $37(42.0)^{* * *}$ & $32(36.4)^{* * *}$ & $23(26.1)^{* * *}$ \\
\hline Placebo & $16(18.4)$ & $12(13.8)$ & $9(10.3)$ \\
\hline
\end{tabular}

Notes: $* * * * P<0.001$ versus placebo; $t P<0.05$; $t+p<0.01$; $t$ tt $P<0.001$ versus salmeterol-fluticasone; $\mathbb{\pi} P<0.05$ versus indacaterol $150 \mu \mathrm{g}$.

Abbreviations: $\mathrm{n}$, number of patients who achieved an improvement; $\mathrm{FEV}_{\text {, }}$, forced expiratory volume in one second.

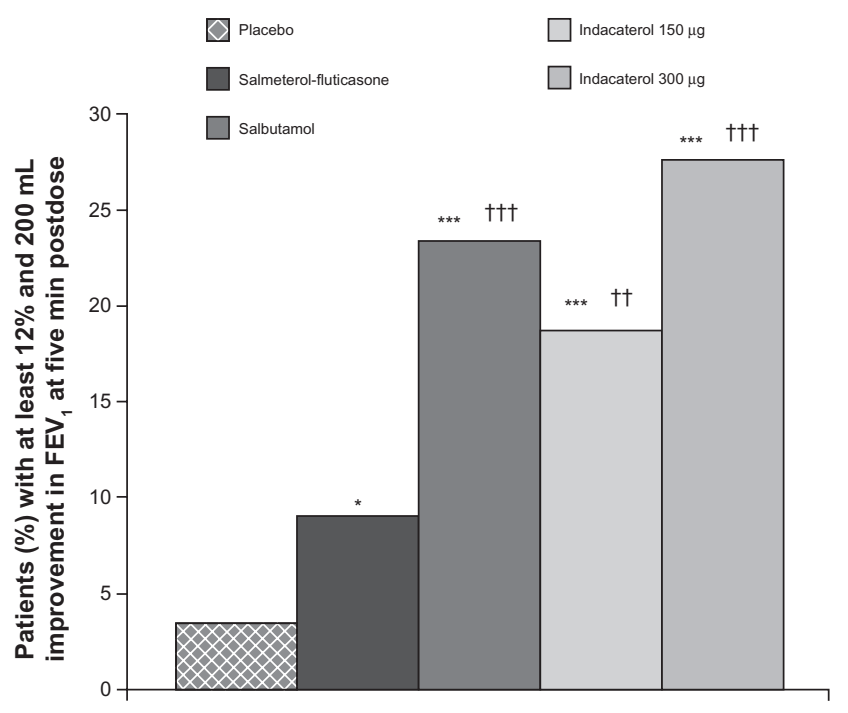

Figure 5 Proportion of patients with a $\geq 12 \%$ and $200 \mathrm{~mL}$ improvement in FEV at five minutes postdose.

Notes: ${ }^{*} P<0.05$; $* * * P<0.001$ versus placebo; ${ }^{\dagger+} P \leq 0.01$; ${ }^{t+t} P \leq 0.001$ versus salmeterol-fluticasone for odds ratio (likelihood of achieving this improvement). Abbreviations: FEV , forced expiratory volume in one second.

of action, both indacaterol doses demonstrated bronchodilator efficacy at least as good as salmeterol-fluticasone for the remainder of the two-hour assessment period.

There was a low incidence of adverse events, all of which were mild or moderate in severity and not suspected of being related to the study drug, as expected in a single-dose study. There were no deaths or discontinuations due to adverse events. There were no serious adverse events or significant adverse events reported and no clinically meaningful differences between the treatments with respect to the numbers and types of adverse events reported. The overall safety data collected indicate that single doses of indacaterol 150 and $300 \mu \mathrm{g}$ have a good overall safety profile.

\section{Conclusion}

Single doses of indacaterol 150 and $300 \mu \mathrm{g}$ demonstrated a fast onset of action, similar to that of salbutamol and faster than that of salmeterol-fluticasone.

\section{Acknowledgments}

The authors thank the patients who took part in the study and the staff at the participating clinical centers. The authors acknowledge Salil Bose, professional medical writer (Novartis), and David Young (Novartis) for assistance in the preparation of this manuscript.

\section{Disclosure}

This study was funded by Novartis Pharma AG, Basel, Switzerland. Mark Higgins, Roger Owen, Carolynn Amos, 
and Ben Kramer are employees of Novartis. Beatrix Balint and Henrik Watz have no actual or potential conflict of interest, including any financial relationships with industry (eg, employment, consultancies, stock ownership, honoraria, expert testimony), either directly or through immediate family.

\section{References}

1. Lopez AD, Shibuya K, Rao C, et al. Chronic obstructive pulmonary disease: Current burden and future projections. Eur Respir J. 2006;27:397-412.

2. Mathers CD, Loncar D. Projections of global mortality and burden of disease from 2002 to 2030. PLoS Med. 2006;3:e442.

3. Global strategy for diagnosis, management, and prevention of COPD. Available at: http://www.goldcopd.com/Guidelineitem. asp?11=2\&12=1\&intId=2003. Accessed Mar 2, 2010.

4. DiMatteo MR. Variations in patients' adherence to medical recommendations: A quantitative review of 50 years of research. Med Care. 2004;42:200-209.

5. Rand CS. Non-adherence with asthma therapy: More than just forgetting. J Pediatr. 2005;146:157-159.

6. World Health Organization. Adherence to long-term therapies: Policy for action. Meeting report 2001 Jun 4-5. Available at: http://www.who. int/chronic_conditions/adherence/en/. Accessed Jul 29, 2010.

7. Bourbeau J, Bartlett SJ. Patient adherence in COPD. Thorax. 2008; 63:831-838.
8. Cazzola M, Matera MG, Lotvall J. Ultra long-acting beta 2-agonists in development for asthma and chronic obstructive pulmonary disease. Expert Opin Investig Drugs. 2005;14:775-783.

9. Naline E, Trifilieff A, Fairhurst RA, Advenier C, Molimard M. Effect of indacaterol, a novel long-acting beta2-agonist, on isolated human bronchi. Eur Respir J. 2007;29:575-581.

10. Beeh KM, Derom E, Kanniess F, Cameron R, Higgins M, van As A. Indacaterol, a novel inhaled beta2-agonist, provides sustained 24-h bronchodilation in asthma. Eur Respir J. 2007;29:871-878.

11. Beier J, Chanez P, Martinot JB, et al. Safety, tolerability and efficacy of indacaterol, a novel once-daily beta(2)-agonist, in patients with COPD: A 28-day randomised, placebo controlled clinical trial. Pulm Pharmacol Ther. 2007;20:740-749.

12. Rennard S, Bantje T, Centanni S, et al. A dose-ranging study of indacaterol in obstructive airways disease, with a tiotropium comparison. Respir Med. 2008;102:1033-1044.

13. Miller MR, Hankinson J, Brusasco V, et al. Standardisation of spirometry. Eur Respir J. 2005;26:319-338.

14. Bauwens $O$, Ninane $V$, van de Maele B, et al. 24-hour bronchodilator efficacy of single doses of indacaterol in subjects with COPD: Comparison with placebo and formoterol. Curr Med Res Opin. 2009; 25:463-470.

15. Cramer JA, Bradley-Kennedy C, Scalera A. Treatment persistence and compliance with medications for chronic obstructive pulmonary disease. Can Respir J. 2007;14:25-29.

16. Donohue JF. Minimal clinically important differences in COPD lung function. COPD. 2005;2:111-124.

17. Santus P, Matera MG, Carlucci P, et al. Onset of action of salmeterol/fluticasone (SFC) in single inhaler vs salmeterol (S) in patients with COPD. Eur Respir J. 2003;22 Suppl:285.
International Journal of COPD

\section{Publish your work in this journal}

The International Journal of COPD is an international, peer-reviewed journal of therapeutics and pharmacology focusing on concise rapid reporting of clinical studies and reviews in COPD. Special focus is given to the pathophysiological processes underlying the disease, intervention programs, patient focused education, and self management protocols.

\section{Dovepress}

This journal is indexed on PubMed Central, MedLine and CAS. The manuscript management system is completely online and includes a very quick and fair peer-review system, which is all easy to use. Visit $\mathrm{http}: / /$ www.dovepress.com/testimonials.php to read real quotes from published authors. 